\title{
Thermogravimetry Q-TG studies of surface properties of lunar nanoparticles
}

\author{
P. Staszczuk
}

Received: 10 May 2010/Accepted: 21 June 2011/Published online: 7 July 2011

(C) The Author(s) 2011. This article is published with open access at Springerlink.com

\begin{abstract}
Using special thermogravimetry Q-TG method, physicochemical properties of lunar sample surfaces were investigated. The numerical and analytical procedures for the evaluation of energetic heterogeneous properties on the basis of liquid thermodesorption from the sample surfaces under the quasi-equilibrium conditions are presented. The calculations of the adsorption capacity and energy distribution functions of liquids on lunar surfaces on the basis of the thermogravimetry data are presented.
\end{abstract}

Keywords Lunar nanoparticles - Thermogravimetry Q-TG · Adsorption capacity · Energetical heterogeneity · Desorption energy distribution functions

\section{Introduction}

The lunar samples of Apollo missions were investigated and presented in detail in the article [1]. From the studies of surface properties of lunar regolith from Apollo 11 (mare), 12 (mare) and 16 (highland) presented in an article [2], it appears that no significant differences in the sorption properties of nitrogen, krypton, $n$-heptane, $n$-octane and water have been detected from samples. Lunar samples possess very low specific surface areas, little nanoporosity

This article was presented during $32^{\text {nd }}$ International Conference on Vacuum Microbalance and Thermoanalytical Conference, Kazimierz Dolny, June 21-24, 2009, Poland.

\section{P. Staszczuk ( $\square)$}

Chair of Bionanomaterials, Institute of Biotechnology, Faculty of Mathematics and Natural Sciences, The John Paul II Catholic University of Lublin, Konstantynów 1H Str., 20-708 Lublin, Poland

e-mail: pstaszczuk@kul.lublin.pl and physicochemical properties between hydrophobic and hydrophilic.

The lunar regolith samples from NASA (Huston, USA) were obtained by our laboratory after a very long time and procedure of projects [3-5]. Very small amounts of three lunar samples from Apollo 11, 12 and 16 missions were personally examined. The thickness of the adsorbed liquid layers (adsorption capacity) and adsorbate-adsorbente interactions (desorption energy) on the lunar nanoparticles can be assessed by means of immersion mode of the sample surfaces [6]. Adsorption and desorption processes on the lunar surfaces include mass and energetic interactions between the adsorbent and adsorbate molecules and atoms.

The obtained experimental data of the liquid-programmed thermodesorption under the quasi-isothermal conditions were worked out on the theoretical basis and methods of calculating the desorption energy distribution functions $[7,8]$ to estimate the total heterogeneity of solid surfaces [9] and fractal coefficients [10].

This article presents studies of adsorption and energetic heterogeneous properties of lunar samples by means of the special thermogravimetry Q-TG technique patented by Paulik's in eight countries [11-14]. The calculations of the desorption energy distribution functions of liquids on lunar nanoparticles have been presented.

\section{Experimental}

\section{Materials}

Three samples from Apollo 11 (A11), 12 (A12) and 16 (A16) missions were studied. Samples consist of weakly coherent fines of diameter in the sub-millimeter range [2]. 
Five basic particle types make up the lunar samples: mineral fragments, pristine crystalline rock fragments, breccia fragments, glass of various kinds and the unique lunarstructured particles-agglutinates [1]. Its composition depends on the mission landing sites [2]. The adsorption of atmospheric components (nitrogen, oxygen, water) could take place before the measurements because sample vessels (Fig. 1) were opened in the air atmosphere.

\section{Apparatus}

Adsorption of apolar (toluene and $n$-octane) and polar (water and $n$-butanol) liquid layers were measured using the derivatograph Q-1500 D (MOM, Hungary) [6, 11-14]. The samples were dried at $150{ }^{\circ} \mathrm{C}$ and saturated with liquid vapours in the vacuum dessicator at $\mathrm{p} / \mathrm{p}_{\mathrm{o}}=1$. The $\mathrm{Q}-\mathrm{TG}$ mass loss and Q-DTG derivative mass loss curves were measured using conical crucible under the quasi-isothermal conditions in the temperature range $20-250{ }^{\circ} \mathrm{C}$ at a heating rate of $6{ }^{\circ} \mathrm{C} / \mathrm{min}$.

\section{Results and discussion}

The Q-TG mass loss and the Q-DTG derivative mass loss curves of liquids as a function of temperature from the lunar samples are presented in Fig. 2. The characteristic inflections in the Q-DTG curves correspond to the individual stages of thermodesorption of water from studied surfaces of A11 and A16. It can be considered as a certain type of spectrum of water thermodesorption process describing an energetic state of polar molecules on surfaces [15].

In Fig. 2, A11 spectrum on Q-DTG curve indicates small inflections near $50^{\circ} \mathrm{C}$ long wide peak with the minimum near $100-110^{\circ} \mathrm{C}$ and a few other small peaks above $140{ }^{\circ} \mathrm{C}$. For $\mathrm{A} 12$ and A16 samples during thermodesorption of $n$-butanol and water, one long peak was

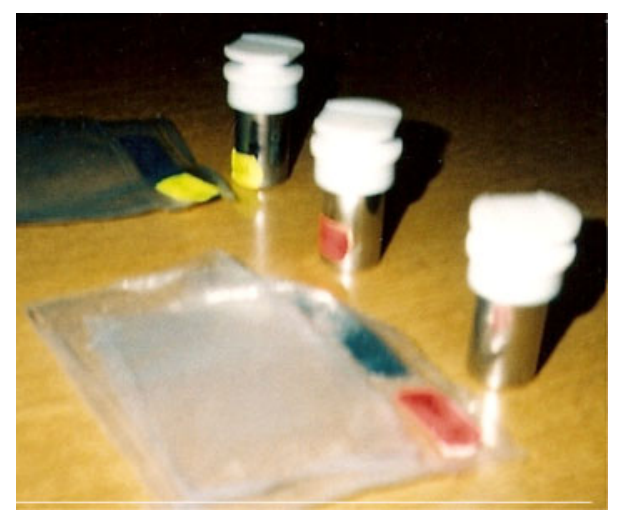

Fig. 1 Sample vessels with A11, A12 and A16 lunar nanoparticles obtained at $110-120{ }^{\circ} \mathrm{C}$ on Q-DTG curves. It is shown from the data presented in Table 1 that the samples are highly sensitive to water and $n$-butanol vapour because the mechanism of adsorption processes depend largely on the interactions of adsorbed molecules with surface active centres.

The amounts of adsorbed water and $n$-octane vapours for $1 \mathrm{~g}$ of dry adsorbent (i.e. adsorption capacity) tend to change in the direction A11 $<$ A12 $>$ A16. The amounts of adsorbed vapours of toluene and $n$-octane are in the decreasing order $\mathrm{A} 11>\mathrm{A} 12>\mathrm{A} 16$.

The chosen Q-TG and Q-DTG curves (Fig. 2) obtained from the studies of thermodesorption of the
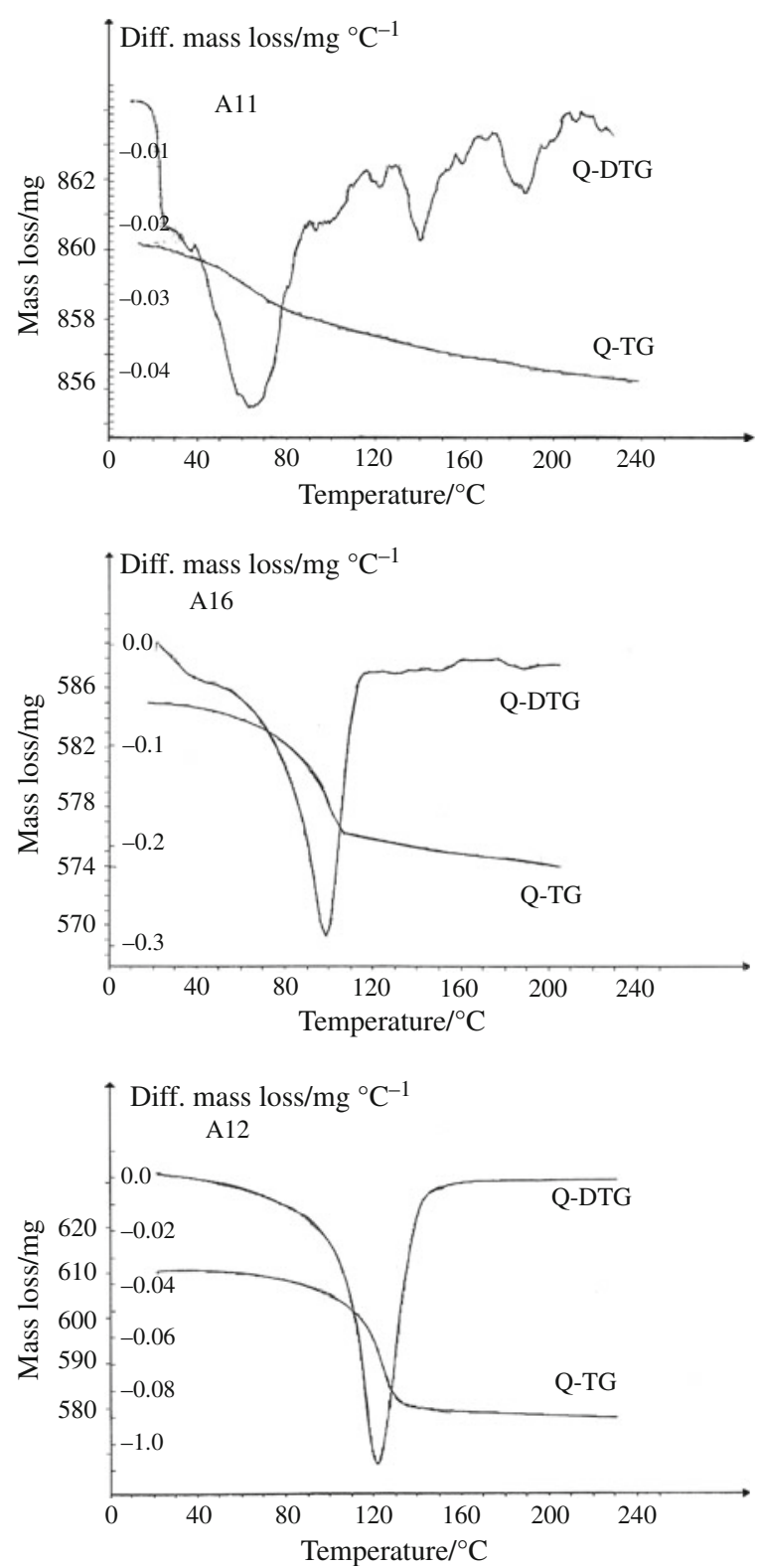

Fig. 2 Thermodesorption Q-TG and Q-DTG curves of liquids from $A 11$ (water), A12 (n-butanol) and A16 (water) from lunar surfaces 
Table 1 Adsorption capacity of tested samples

\begin{tabular}{llllllllll}
\hline Samples & $\begin{array}{l}\text { Sample } \\
\text { mass/mg }\end{array}$ & $\begin{array}{l}\text { Water/ } \\
\mathrm{mg}\end{array}$ & $\begin{array}{l}\text { Water mmol/ } \\
\mathrm{g} 10^{-2}\end{array}$ & $\begin{array}{l}n \text {-butanol/ } \\
\mathrm{mg}\end{array}$ & $\begin{array}{l}n \text {-butanol/mmol/ } \\
\mathrm{g} 10^{-2}\end{array}$ & $\begin{array}{l}\text { Toluene/ } \\
\mathrm{mg}\end{array}$ & $\begin{array}{l}\text { Toluene/mmol/ } \\
\mathrm{g} 10^{-2}\end{array}$ & $\begin{array}{l}n \text {-octane/ } \\
\mathrm{mg}\end{array}$ & $\begin{array}{l}n \text {-octane/mmol/ } \\
\mathrm{g} 10^{-2}\end{array}$ \\
\hline A11 & 856 & 3.5 & 22.7 & 6.6 & 10.4 & 6.7 & 8.5 & 5.2 & 5.3 \\
A12 & 578 & 13.3 & 12.9 & 32.2 & 75.3 & 4.8 & 9.0 & 1.5 & 2.3 \\
A16 & 574 & 11.1 & 10.7 & 24.1 & 56.7 & 1.3 & 2.4 & 1.1 & 1.7 \\
\hline
\end{tabular}

abovementioned liquids describe the energetic state of their molecules in intra- and inter-grain pores of the material structure and in the interior pores of lunar samples. The energy of interactions among molecules depends on the adsorbate type, properties of the surface on which they are adsorbed and small sample porosity (presence of micropores). The differential Q-DTG curves are characterized by the presence of one ( $n$-butanol) because the continuity of the thermodesorption process and monotonic changes of adsorption layer properties depends on the distance of liquid molecules from the surface. A few distinct peaks of water indicate the presence of water molecules on the surface in different interaction states. In the case of thermodesorption of water from the surfaces in temperatures of $100-120^{\circ} \mathrm{C}$, the obtained Q-DTG curves are in the form of broad band resulting from some amount of vapours of the molecules adsorbed and large differentiation of the energetic system. Interpretation of the thermodesorption curves also consists in determination of the amount of liquids bound in the form of adsorption monolayer (so-called vicinal adsorbate) of individual liquids present on the sample surfaces.

The energetic heterogeneity of materials is conditioned by the differences in topology of the adsorption centres, dispersion of pore size and other factors. New information about energetic heterogeneity of examined samples can be obtained from desorption energy distribution function. In the case of the application of analytical method for the evaluation of desorption energy distribution from Q-TG and Q-DTG curves, the equation of desorption kinetics for the part of surface characterized by constant value of desorption energy $E_{\mathrm{d}}$ has the following form [7, 16]:

$-\frac{\mathrm{d} Q}{\mathrm{~d} t}=(1-Q) \exp \left(-\frac{E_{\mathrm{d}}}{R T}\right)$

where

$T=T_{\mathrm{o}}+\beta t$

$R$ is the universal gas constant, $Q$ is the degree of surface coverage, $v$ is the entropy factor, $E_{d}$ is the desorption energy calculated for each temperature, $T_{\mathrm{o}}$ and $T$ are the initial and given temperatures of desorption, respectively, $\beta$ is the heating rate of the sample and $t$ is the time.
Equation 1 holds for the case when the amount of desorbed substances does not fill the whole surface uniformly; however, desorption takes place in the range of capillary condensation. The above equation can be also used for the analysis of desorption from the multilayer filled energetically heterogeneous surface of the material studied. Then, the desorption rate is described by the integral equation [17]:

$-\frac{\mathrm{d} Q}{\mathrm{~d} t}=\int \rho\left(E_{\mathrm{d}}\right)(1-Q)\left(\frac{v}{\beta}\right) \exp \left(\frac{E_{\mathrm{d}}}{R T}\right) \mathrm{d} E_{\mathrm{d}}$

Energetic heterogeneity of the solid surface is described by the energy distribution function $\varphi\left(E_{\mathrm{d}}\right)$. In other words, this is the density of adsorption centre distribution probability on the surface of the studied sample in relation to the quantity of desorption energy.

The logarithmic form of the initial equation is expressed by the following formula:

$\ln \left\{-\left[\frac{1}{1-Q}\right]\left(\frac{\mathrm{d} Q}{\mathrm{~d} T}\right)\right\}=f\left(\frac{1}{T}\right)$

The final expression for determination of desorption energy distribution $\rho(E)$ can be expressed in the form [8-10]:

$\rho\left(E_{\mathrm{d}}\right)=-\left(\frac{\mathrm{d} Q}{\mathrm{~d} T}\right)\left(\frac{1}{T}\right)$

Equation 5 was used for the calculation of desorption energy distributions, $\rho\left(E_{\mathrm{d}}\right)$, from the pores for each temperature $T$ in the Q-TG and Q-DTG curves. The results of calculation desorption energy for the selected systems for liquids desorption from the surfaces within the temperature range $T=50-180{ }^{\circ} \mathrm{C}$ are presented in Table 2. The $E_{\mathrm{d}}$ values range $15.2-42.1 \mathrm{~kJ} / \mathrm{mol}$ for water, $15.6-47.9 \mathrm{~kJ} / \mathrm{mol}$ for $n$-butanol, $12.1-16.8 \mathrm{~kJ} / \mathrm{mol}$ for toluene and $8.5-10.5 \mathrm{~kJ} / \mathrm{mol}$ for $n$-octane. In the case of

Table 2 The maximum of peaks desorption energy values of liquids, $E_{\text {dmax }}, \mathrm{kJ} / \mathrm{mol}$

\begin{tabular}{llllc}
\hline Samples & Water & $n$-Butanol & Toluene & $n$-Octane \\
\hline A11 & 15.2 & 15.6 & 16.8 & 10.5 \\
A12 & 42.1 & 47.9 & 15.9 & 9.2 \\
A16 & 40.5 & 30.1 & 12.1 & 8.5 \\
\hline
\end{tabular}


water and $n$-butanol, the high value of desorption energy presented in Table 2 indicates the great influence of the lunar surfaces on adsorbed of polar molecules.

Figure 3 presents, for example, desorption energy distribution functions for A11 (water and toluene), A12 ( $n$ butanol) and A16 (water, $n$-butanol) of liquids on lunar samples. The typical Gauss (A12, A16 samples) and bimodal shapes of the adsorption site distribution associated with the desorption of water and $n$-butanol (A11 sample) from the surfaces may be observed.

The desorption energy for water and toluene on the A11 lunar material exhibit a few maxima which suggests the
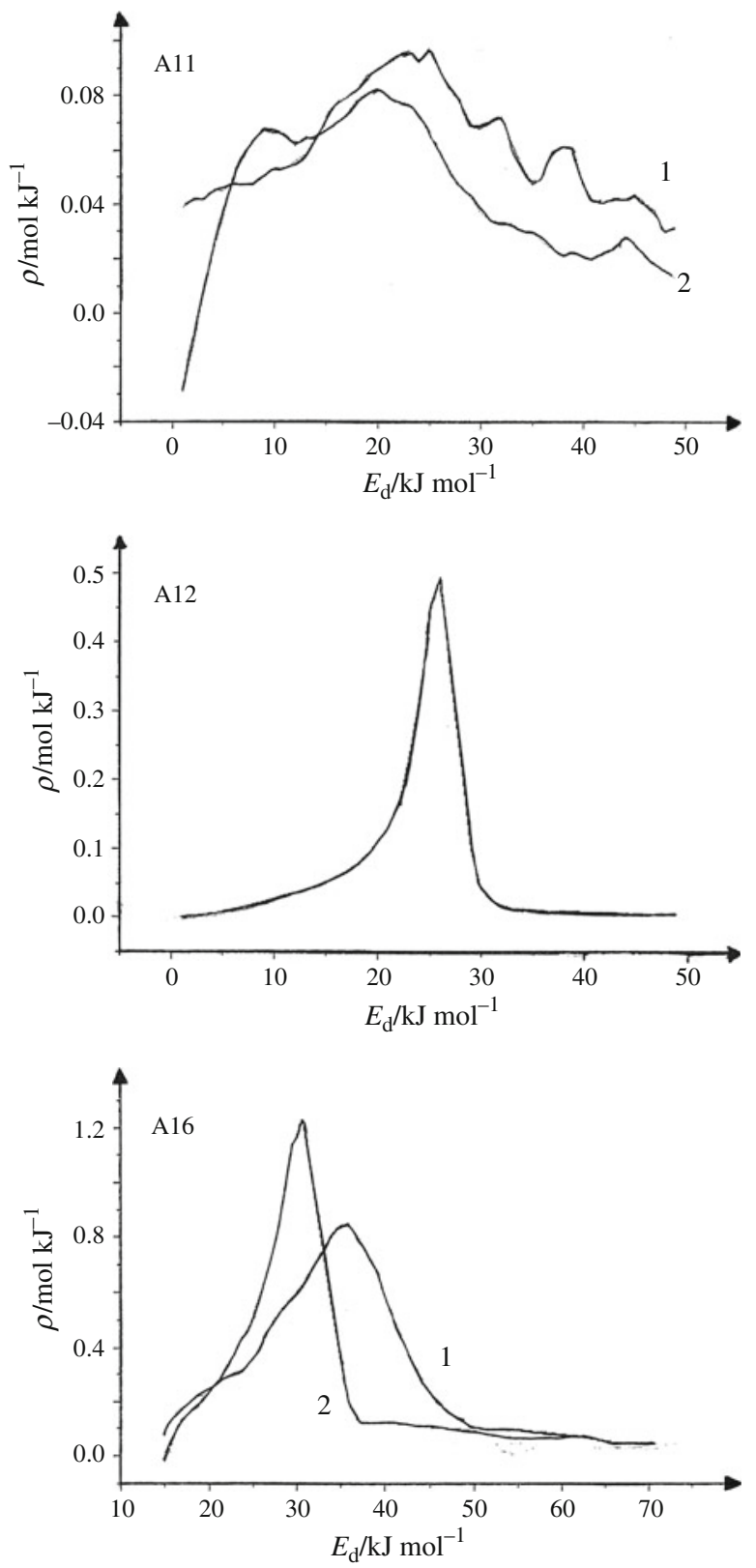

Fig. 3 Desorption energy distribution functions for samples: A11 ( 1 toluene, 2 water), $A 12$ ( $n$-butanol) and A16 ( 1 water, $2 n$-butanol) presence of three different types of active sites for the sample under examination. For polar liquids, a considerable increase of energy desorption value occurred in the creation of high-energy interactions between the molecules and surface studied. However, changes in the distribution of adsorption sites which occur as a result of mechanical and chemical treatment before our experiments (e.g. during previous investigations, adsorption from air) appear somewhat complicated. The above treatment resulted in the creation of new energy adsorption sites for the adsorbed molecules. The thermodesorption of the above liquids shows that the investigated materials have nonporous properties and more hydrophobic than hydrophilic properties.

\section{Conclusions}

The shape of Q-TG curves mass loss of polar and apolar liquids thermodesorption from the lunar samples is characterized by single and double steps, which indicates monotonic (continuous) and nonmonotonic changes of properties of liquid adsorption layers adsorbed on the surface. The presence of single inflexions on the Q-TG curves results from the determined bonding energy of liquid molecules with the surface of studied sample as well as in the adsorption layers. The differential mass loss curves Q-DTG describe the kinetics of thermodesorption of studied liquids from lunar nanomaterial lunar surface. They are characterized by a distinct peak, which is associated with the evaporation of liquid molecules being in similar energetic states in the adsorption layer.

The energetic heterogeneity properties from the thermogravimetry Q-TG data were determined by means of the analytical-numerical method. Desorption energies and desorption energy distribution functions were calculated from the Q-TG and Q-DTG data. The shape of the desorption energy distribution function curves are of the Gauss type with one and double evident peaks. On the basis of the obtained results, it appears that the lunar surfaces possess rather hydrophobic properties.

Acknowledgements The samples had been kindly placed for my disposal by the NASA Luna sample curator, Dr. Gary Lofgren, Huston, Texas, USA.

Open Access This article is distributed under the terms of the Creative Commons Attribution Noncommercial License which permits any noncommercial use, distribution, and reproduction in any medium, provided the original author(s) and source are credited.

\section{References}

1. Heiken GH, Vaniman DT, French BM, editors. Lunar sourcebook. Cambridge: Cambridge University Press; 1991. 
2. Robens E, Bishoff A, Scheiber A, Unger KK. Investigation of surface properties of lunar regolith. J Therm Anal Calorim. 2008;94(3):627-31.

3. Staszczuk P. Investigation of surface structure and water sorption properties of lunar reoligh. Research Program. Sent to NASA, Huston; 5 July 2003.

4. Robens E, Staszczuk P. Investigation of physicochemical properties of lunar regolith samples. Research Program. Sent to NASA, Huston; Sep 2003.

5. Robens E. Investigation of physicochemical properties of lunar regolith samples. Research Program. Sent to NASA, Huston; 3 March 2006.

6. Staszczuk P. Surface properties of nanoparticles. In: Brown ME, Gallagher PK, editors. Handbook of thermal analysis and calorimetry. Volume 5: recent advances. Techniques and applications, Chapter 10. Oxford: Elsevier; 2008. p. 343-92.

7. Bogillo VI, Staszczuk P. Characterization of the structural and energetic heterogeneity of mesoporous solid surface from Q-DTG data. J Therm Anal Calorim. 1999;55:493-510.

8. Staszczuk P, Sternik D, Kutarov VV. Analysis of the energetic heterogeneity of $\mathrm{HgBa}_{2} \mathrm{Ca}_{2} \mathrm{Cu}_{3} \mathrm{O}_{8+\mathrm{x}}$ surfaces Q-TG and Q-DTG data. J Therm Anal Calorim. 2002;69:23-6.

9. Staszczuk P, Kutarov VV, Płanda M. Total heterogeneity of $\mathrm{Al}_{2} \mathrm{O}_{3}$ surface. Programmed $n$-octane thermodesorption under quasi-isothermal conditions. J Therm Anal Calorim. 2003;71:445-58.
10. Staszczuk P, Sternik D, Chądzyński GW. Determination of total heterogeneous properties and fractal dimension of high-temperature superconductors. J Therm Anal Calorim. 2004;71:173-82.

11. Paulik F, Paulik J. Thermoanalytical examination under quasiisothermal-quasi-isobaric conditions. Thermoichim Acta. 1986; 100:23-59.

12. Paulik F, Gal S, Meszaros Szecsenyi K. A new method for the microdistillation of liquids using quasi-isothermal quasi-isobaric thermogravimetry. J Therm Anal. 1994;42:425-35.

13. Paulik F. Special trends in thermal analysis. Chichester: Wiley; 1995.

14. Paulik F. Fourty years of thermal analysis in Hungary. J Therm Anal. 1996;47:659-71.

15. Staszczuk P, Majdan M, Pikus S, Sternik D, Błachnio M. Studies of surface properties of pure and modified by $\mathrm{Mn}^{2+}$ and $\mathrm{Ni}^{2+}$ ions of aluminium oxide samples using complex methods. J Therm Anal Calorim. 2008;94:655-62.

16. Karge HG, Dondur V. Investigation of the distribution of acidity in zeolites by temperature-programmed desorption of probe molecules. J Phys Chem. 1990;94:765-72.

17. Hunger B, Szombathely MV, Hoffmann J, Brauer P. Characterization of the acidic properties of zeolites by means of temperature-programmed desorption (TPD) of ammonia. Calculation of distribution function of the desorption energy. J Therm Anal Calorim. 1995;44:293-303. 